\title{
Seriedade e subversão em Kanaken-Gandhi, de Osman Engin
}

\author{
Seriousness and subversion in Kanaken-Gandhi, by Osman Engin
}

Dionei MATHIAS*
Universidade Federal de Santa Maria (UFSM)

RESUMO: No processo de definição e imposição de verdades, a seriedade tem um papel fundamental, pois ela sugere que o comportamento daqueles que a detêm está embasado num interesse probo. Acompanhada de um aparato de controle, às vezes, também de violência, a seriedade pode representar um mecanismo para dominar o outro. A subversão dessa organização do espaço demanda um sujeito apto a questionar as verdades estabelecidas e a defender-se da provável violência a ser esperada em resposta ao questionamento. Em seu romance satírico Kanaken-Gandhi, Osman Engin mostra esse processo, confrontando o estrangeiro com as autoridades, revelando a forma como a seriedade é utilizada para intimidar o estrangeiro e indicando o modo como a subversão se concretiza a partir do riso.

PALAVRAS-CHAVE: Osman Engin. Kanaken-Gandhi. Seriedade. Subversão. Riso.

ABSTRACT: In the process in which truth is defined and imposed, seriousness plays a central role. It suggests that the behaviour of those who show it is based on a virtuous interest. Along with a control apparatus, sometimes, with violence, seriousness can represent a mechanism to dominate others. The subversion of this space organization needs a subject able to question the established truths and to defend himself from the prospective violence to be expected in answer to his questioning. In his satirical novel Kanaken-Gandhi, Osman Engin shows this process by confronting foreigners and authorities, by revealing the way seriousness is used to intimidate foreigners and by pointing out how subversion begins to materialize with the principle of laughter.

KEYWORDS: Osman Engin. Kanaken-Gandhi. Seriouness. Subversion. Laughter.

Recebido em 18 de outubro de 2016. Aprovado em 3 de dezembro de 2016.

\footnotetext{
* Doutor em Letras pela Universidade de Hamburgo e pela Universidade Federal do Paraná. Professor do Departamento de Letras Estrangeiras Modernas, na Universidade Federal de Santa Maria - RS. Email: dioneimathias@gmail.com.
} 


\section{Introdução}

$\mathrm{O}$ riso talvez represente, antes de mais nada, um modo de afirmar a vitalidade. Com o estardalhaço da gargalhada, o sujeito desafia a imposição do silêncio e a hostilidade da selva humana, afirmando sua presença de modo a não permitir que seja ignorado. Com o desejo de produzir risadas ruidosas e afirmar um princípio vital dinâmico e flexível, o romance satírico Kanaken-Gandhi ('O Gandhi dos canacas') escrito em 1998, por Osman Engin, configura um esforço de articular uma voz num espaço social cuja distribuição de poder é desigual e cujo entorno se caracteriza por um comportamento pouco amistoso e acolhedor. O protagonista desse romance - alvo e produtor das risadas - é o estrangeiro, em suas tentativas de encontrar um lugar de fala num novo contexto sociocultural, mais especificamente, o turco Osman em terras germânicas. Se o tom desse romance fosse melancólico, seu título poderia muito bem ser "os sofrimentos do velho Osman", sendo possível reconstruir diversas analogias ao texto de Goethe. Isso, contudo, significaria curvar-se diante da lei do mais forte. No lugar da submissão, o romance se inscreve na tradição da sátira, mostrando um protagonista autoconfiante e que ataca as mazelas do espaço social em que se encontra. Nisso a voz narrativa ataca a cultura receptora, mas também põe em cena as limitações do próprio estrangeiro, como argumenta Yeşilada (1997, p. 538).

Numa entrevista concedida ao jornal Die Tageszeitung, em 13 de dezembro de 1994, o autor discute suas intenções ao satirizar elementos da sociedade alemã:

Taz: Was ist dein gesellschaftspolitisches Anliegen?

Osman Engin: Satire hat ohnehin nur ein gesellschaftspolitisches Anliegen. Satire dient dazu, auf Punkte zu zeigen, die nicht richtig sind, die menschenfeindlich oder menschenverachtend sind. Sie zeigt auf wunde Punkte in der Gesellschaft, damit man darüber nachdenkt. Satire selbst kann den Zustand ja nicht verbessern (ENGIN/YEŞILADA, 1994) ${ }^{1}$.

Na mesma entrevista, afirma que os dois elementos da sociedade alemã que mais critica em sua obra são a burocracia e a xenofobia, aproveitando o ensejo para reforçar que em seus

1 "Taz: Qual teu objetivo sociopolítico?

Osman Engin: As sátiras, de qualquer modo, têm um objetivo sociopolítico. As sátiras servem para mostrar elementos que não estão certos, que são anti-humanos ou que desprezam a humanidade. Elas mostram feridas da sociedade para que se reflita sobre isso. A sátira mesma não pode melhorar a situação". 
textos também ridiculariza os comportamentos dos imigrantes turcos, como a hipocrisia moral, cujo teor o incomoda. Nesse posicionamento, o autor deixa bem clara a importância que atribui à responsabilidade política pessoal, isto é, à necessidade de tomar a frente dos acontecimentos que configuram uma sociedade, a fim de criar ou imaginar um espaço social que assegure uma existência digna a todos os seus membros. Mesmo reconhecendo os limites da obra literária quanto a seu potencial concreto de mudar determinados aspectos da vida social, o autor alimenta o desejo de desencadear reflexões, que, por sua vez, podem representar o início de uma reformulação de valores, uma vez que incluem a percepção da hostilidade que se esconde por trás de normas de comportamento.

Osman Engin tem um interesse biográfico em refletir e atacar as misérias alemãs, em se tratando da situação dos estrangeiros. Nascido em 1960 em Izmir, na Turquia, ele chegou à Alemanha aos 13 anos, passando pelo sistema universitário alemão ao contrário de muitos imigrantes, e se estabelecendo como um dos mais importantes satiristas das mídias impressas e televisivas nacionais. Sua história é a história de um imigrante de sucesso, não somente em questões econômicas, mas sobretudo como indivíduo que desenvolve e articula sua própria voz no espaço social em que transita. A partir desse posicionamento no mundo, seu projeto literário, que reúne a tradição da sátira afeita a um regime autoritário na Turquia e que dialoga com a herança dos satiristas alemães (TERKESSIDIS, 2007, p. 294), chama a atenção para alguns aspectos que o incomodam, sem, nisso, reduzir, sua escrita a uma literatura puramente engajada ou panfletista. Trata-se, antes, de um exercício de visão, em que a sátira distorce excertos da realidade, a fim de revelar o caráter absurdo de algumas coordenadas da organização social e, ao mesmo tempo, exercitar a visão da complexidade que envolve a existência, especialmente, no encontro intercultural. Nas palavras da pesquisadora Irmgard Ackermann: "Satiric representations of the Other (here the Germans) offer a particularly fitting means for critical engagement with the Other. Satire does not claim to be objective. It strives to depict not individual figures but representative types, even when they are given names" (1995, p. 528). Os textos de Engin apresentam a mordacidade típica das sátiras, mas eles não são hostis. Pelo contrário, a despeito dos ataques, há um tom conciliador que deseja mostrar, com o intuito de possibilitar interações mais pacíficas e dignas para os membros 
envolvidos. O que predomina nessa aproximação é o riso, como afirmação da vida e como chance de diálogo.

O título do romance condensa essa afirmação. No português a palavra "Kanaken" designa os nativos da Polinésia e de várias ilhas da Oceania, já no alemão ela é usada de modo pejorativo para designar estrangeiros. Ao utilizar esse termo no lugar mais destacado de seu texto, com todas suas conotações negativas, Engin se apropria dela, como vários representantes de outras minorias, para transformá-la em expressão de orgulho. Desse modo, a palavra antes utilizada para ofender sofre uma alteração semântica num sentido contradiscursivo, para indicar a presença autoconfiante do ofendido e seu direito à voz própria.

\section{Considerações sobre o riso}

Dentre as diversas teorias do riso e da comicidade, talvez a proposta de Bakhtin seja a mais adequada neste contexto para discutir as inquietações aventadas no romance Kanaken-Gandhi. Trata-se de uma teoria que compreende o riso como energia renovadora que se estabelece justamente no embate entre diferentes atores sociais. Em seu texto seminal, em que discute a obra de Rabelais, Bakhtin (1987) contrapõe dois grupos: o povo e a igreja, ambos com interesses diversos e que, na defesa dos mesmos, se chocam, provocando uma dinâmica de imposição e renovação. Para esta análise, queremos resgatar três elementos desenvolvidos pelo pensador russo para nos aproximarmos do texto de Engin: (1) o papel da seriedade como mecanismo de imposição de autoridade e verdade, (2) o papel do corpo entre subjugação e liberdade, por fim, (3) a dinâmica da subversão como caminho de renovação e reposicionamento dos diferentes atores sociais.

A seriedade representa uma estratégia de comportamento e de organização discursiva que permite a encenação de autoridade. A partir da posição privilegiada de poder, inicia-se o processo de instauração e divulgação de verdades. Para Bakhtin (1987, p. 78), a seriedade está estreitamente ligada à intimidação e à produção de medo, ou seja, a superfície corporal serve de instrumento para a produção de sentidos. Estes, por sua vez, têm a função de desencadear efeitos que levam os interlocutores a verem seus próprios corpos tomados por uma sensação de inibição, exigindo um cuidado maior. Enquanto o riso 
surge como um movimento natural, sem antes passar um processo de reflexão cujo intuito reside em antecipar os efeitos a serem produzidos, a seriedade resulta de um processo consciente de encenação da autoridade, a fim de subjugar o outro. Bakhtin escreve:

Assim, a desconfiança diante do sério e a fé na verdade do riso eram espontâneos. Compreendia-se que o riso não dissimulava jamais a violência, que ele não levantava nenhuma fogueira, que a hipocrisia e o engano não riam nunca, mas pelo contrário revestiam a máscara da seriedade, que o riso não forjava dogmas e não podia ser autoritário, que ele era sinal não de medo, mas de consciência de força, que estava ligado ao ato de amor, ao nascimento, à renovação, à fecundidade, à abundância, ao comer e ao beber, à imortalidade terrestre do povo, enfim que ele estava ligado ao futuro, ao novo, ao qual ele abria o caminho. É por essa razão que, espontaneamente, se desconfiava da seriedade e se punha fé no riso festivo. (1987, p. 82)

Essa interpretação dicotômica do riso e da seriedade talvez tivesse que ser diferenciada para a prática nos séculos XX e XXI, já que o riso também passou a representar um mecanismo de encenação com o objetivo de silenciar o outro por meio da superioridade vital, ao passo que a seriedade se transformou em reflexo desse silenciamento. Ou seja, o riso e a seriedade não são constantes imutáveis que se concretizam sempre do mesmo modo em cada espaço social, eles são reformulados a cada interação, com um maior ou menor grau de transformação discursiva. Para os objetivos de Osman Engin, a leitura que Bakhtin faz sobre a função da seriedade para a igreja da Idade Média e sobre o riso do povo diante do poder dessa instituição pode ser emprestada para a situação dos estrangeiros perante as autoridades que decidem sobre as permissões de permanência no país. Por um lado, surge um grupo que, com o respaldo da lei, utiliza-se da seriedade para encenar sua autoridade. Por outro lado, aparece um núcleo irreverente de estrangeiros que, a despeito das tentativas de silenciamento e intimidação, não permite que seu ímpeto vital seja rompido, embora sejam confrontados com uma política de produção de terror e desespero. A partir do riso que não se cala, mesmo perante um estado organizado em volta da seriedade e da imposição de verdade, que ameaça a integridade e existência daqueles que não fazem parte do grupo que detém o poder, surge um movimento de subversão que desencadeia um processo de reflexão sobre a disposição do mundo. Nesse 
processo de questionamento, reside um ímpeto de defesa diante do opressor, mas também um potencial de renovação.

Tanto a seriedade como o riso representam disposições do corpo. A seriedade resulta de um processo de autocontrole e manipulação do corpo, a fim de encenar, ao menos no contexto analisado por Bakhtin, sua superioridade sobre aquele que ainda não aprendeu a guiar o corpo a partir das ordens da razão. Interessantemente, a diferença gerada através da vigilância constante do sujeito racional sobre os movimentos faciais ou mesmo de suas vísceras não se transforma em critério para a exclusão do grupo; pelo contrário, a diferença do corpo subordinado ao princípio da seriedade serve para legitimar a autoridade e a imposição da visão de mundo daquele sujeito. A energia dispensada ao processo de domesticação do corpo se transforma em poder. Este, por sua vez, se concretiza como moeda, com a qual o sujeito adquire uma série de prazeres, cuja obtenção recompensa o esforço necessário para disciplinar o corpo.

O corpo daquele que se vê confrontado com a seriedade perpassada de autoridade e, com ela, do poder de violência, também passa por uma transformação em decorrência do medo que surge desse encontro. $\mathrm{O}$ medo, em sua função biológica, desencadeia um alarme para sinalizar ao indivíduo a presença do perigo. Esse alerta, por sua vez, coíbe uma aproximação natural ao outro. O medo força o corpo a antecipar possíveis perigos, para evitar que sua integridade seja violada. Logo, a desconfiança se insere no horizonte anímico do sujeito e passa a funcionar como crivo para a concretização dos sentidos emitidos pelo corpo na interação com o detentor de poder.

Ao contrário das interações embasadas no princípio da seriedade e da desconfiança, que passam por um processo de manipulação de sentidos a fim de impor verdades ou de proteger a integridade, o riso natural, ou seja, aquele que não é utilizado pelo indivíduo para alcançar determinado efeito, se aproxima do outro sem antecipar quaisquer riscos. Esse riso brota de um ímpeto vital que irrefletidamente afirma a vida e deseja expandir seu prazer. Nisso, ele ainda não representa um instrumento nem de captação de benevolência nem de ridicularização (1987, p. 55). Ele reflete uma necessidade do corpo de impor seu direito à vida e ao prazer. Nesse movimento, há uma força libertadora que não permite ser aterrada pela violência ou pelo medo. Bakhtin afirma: 
O riso não é forma exterior, mas uma forma interior essencial a qual não pode ser substituída pelo sério, sob pena de destruir e desnaturalizar o próprio conteúdo da verdade revelada por meio do riso. Esse liberta não apenas da censura exterior, mas antes de mais nada do grande censor interior, do medo do sagrado, da interdição autoritária, do passado, do poder, medo ancorado no espírito humano há milhares de anos. O riso revelou o princípio material e corporal sob a sua verdadeira acepção. $(1987$, p. 81)

Por meio do riso libertador, surge uma verdade alternativa à interpretação de realidade instituída por aqueles que utilizam a seriedade. Essa verdade estabelece outra ordem de mundo, preferindo a inclusão a partir da afirmação da vida à exclusão no marco da diferença.

Intrínseca a esse ímpeto libertador, há uma dinâmica que reposiciona os diferentes atores sociais, estabelecendo uma ordem que inverte a distribuição de poder e revoga o monopólio de verdades. Desse embate de forças entre o riso e a seriedade, surge um espaço virtual, onde é possível imaginar uma organização do espaço social em que se atribui àqueles que foram silenciados pelo medo um lugar de fala. Com a "interrupção provisória de todo o sistema oficial, com suas interdições e barreiras hierárquicas" (BAKHTIN, 1987, p. 77), ou seja, com a neutralização do medo diante de uma instância que ameaça a dignidade pessoal e a integridade do corpo, acompanhada da repartição igualitária do direito à produção de sentidos a orientarem a concretização existencial naquele espaço social, o tempo e o espaço deixam de ser absolutos, para iniciarem um processo de reformulação de valores ou princípios que guiam a formação de identidade e o pertencimento social. No contexto da Idade Média, Bakhtin constata:

Se a face oficial, religiosa, estava orientada para o passado e servia para sancionar e consagrar o regime existente, a face risonha popular olhava para o futuro e ria-se dos funerais do passado e do presente. Ela opunha-se à imobilidade conservadora, à sua "atemporalidade", à imutabilidade do regime e das concepções estabelecidas, punha ênfase na alternância e na renovação, inclusive no plano social e histórico. (1987, p. 70)

Contudo, a subversão que acompanha o riso e o espaço que ele estabelece para a articulação alternativa de vozes representam formas utópicas. O poder da Igreja na Idade 
Média não se via em risco diante do comportamento irreverente do povo. Tampouco os estados contemporâneos se veem afetados pelos risos de seus estrangeiros. Oficialmente tolerado, o não-lugar do riso até produz sentidos, porém seu potencial de transformação em instrumento de percepção ou comunicação é bastante restrito no macrocosmo social. A despeito dessa capacidade moderada de se estabelecer como uma nova visão de mundo, o lugar do riso ensaia diferentes formas de estruturar e enxergar o mundo, despertando no horizonte cognitivo individual a suspeita de que a disposição dos espaços e suas respectivas verdades poderiam ter outra ordem. Nesse ensaio de percepção, reside o potencial de transformação não a curto, mas talvez a longo prazo, preparando, desse modo, o terreno para narrações individuais de identidade que já não sejam mais forçadas à subordinação a verdades instituídas por outros interesses e desejos.

Em seu romance Kanaken-Gandhi, Osman Engin contrapõe duas forças que lembram, em muitos aspectos, a distribuição de poder analisada por Bakhtin. No romance, não é a Igreja e o povo que se chocam, mas sim a Ausländerbehörde (órgão do governo alemão que cuida de assuntos relacionados a imigrantes, concedendo permissões de permanência, de trabalho etc.) e, por outro lado, o estrangeiro. Este, com uma base de direito precária, praticamente não tem voz para articular seus medos, permanecendo, em muitos casos, à margem e em silêncio, a fim de não despertar a ira do anfitrião tolerante. Enquanto isso, o órgão de estrangeiros detém o poder de decidir sobre o futuro do imigrante e de suas famílias. Osman Engin conhece esse mundo e faz um acerto de contas. Sua atitude como intelectual, contudo, não é hostil, pelo contrário, o riso produzido no romance tem o objetivo de renovar e afirmar o direito à vida, também de um estrato social que ainda precisa lutar por seu lugar à fonte que produz sentidos e que orienta a concretização da existência. Nisso satiriza a cultura que recebe o estrangeiro, como argumenta Yeşilada.

\section{Autoridade e seriedade}

O enredo do romance satírico gira em torno do protagonista de origem turca Osman e de sua família que vive há mais de três décadas na Alemanha. No dia do seu quinquagésimo segundo aniversário recebe uma carta da Ausländerbehörde. No lugar da esperada cidadania alemã, Osman recebe um aviso para deixar o país e voltar para a Índia, 
pois seu pedido de asilo foi recusado. O protagonista se dirige ao órgão do governo, a fim de explicar que jamais pediu asilo nem possui a cidadania indiana, porém as informações existentes no banco de dados negam as informações prestadas por Osman. No fim, descobre-se que o filho, no intuito de ajudar o pai de um amigo indiano, utiliza a identidade de seu pai turco para que o indiano possa ficar na Alemanha, o que explica que o destino da extradição é a Índia e não a Turquia. Entre o recebimento da carta de aviso e a extradição, desvelam-se aos olhos do leitor as inúmeras tentativas por parte do protagonista estrangeiro de comunicar-se com as autoridades alemãs. Estas, por vezes, lembram as instâncias arbitrárias e inacessíveis dos textos kafkianos.

A representante da intimidadora da autoridade alemã é a senhora KottzmeyerGöbelsberg, cujo nome de solteira (Kottzmeyer) lembra vômitos e seu nome de casada (Göbelsberg) parece aludir ao ministro de propaganda do regime nazista. Nessa escolha de nomes, o autor já subverte a lei de obediência. O protagonista ainda lembra de seu primeiro encontro com a funcionária:

Ich weiß noch, Frau Kottzmeyer hat mich seinerzeit gefragt: "Was du wollen?" Ich wollte die Beamtin damals nicht enttäuschen und stellte mich deshalb rein sprachlich auf ihr Niveau ein. Ich antwortete im besten Tarzan-Deutsch: "Ich Osman Engin, du schicken Brief, ich kommen. Jane und Chita warten draußen vor Tür. Huga, huga!" (ENGIN, 2002, p. 17)2.

A forma como a funcionária se dirige ao estrangeiro, nessa primeira exposição do encontro entre as duas instâncias, estabelece uma hierarquia, em que o estrangeiro se encontra no degrau inferior. Além de utilizar o pronome tu, que no contexto da língua alemã está reservado para situações informais, portanto inadequado diante da formalidade exigida em todas as negociações legais, ela ainda opta por uma construção gramatical rudimentar de suas frases, indicando sua convicção de que o estrangeiro só se comunica com verbos no infinitivo. A forma irreverente como a voz narrativa relata e encena esse episódio sugere, num primeiro momento, que a distribuição de poder se encontra

\footnotetext{
${ }^{2}$ As traduções dos excertos são minhas. As citações seguem a seguinte edição: ENGIN, Osman. KanakenGandhi. München: DTV, 2002.

"Eu ainda sei o que a senhora Kottzmeyer me perguntou naquele dia: "O que tu querer?" Eu não queria decepcionar a funcionária pública, por isso me adaptei já em questões linguísticas a seu nível. Eu respondi no melhor alemão tipo Tarzan: "Eu Osman Engin, tu enviar carta, eu vir. Jane e Chita esperar em frente de porta. Uga, uga!".
} 
equilibrada, sem oferecer qualquer ameaça à situação do estrangeiro. Contudo, basta tirar a pátina do cômico e do exagero, cuja função em textos satíricos é deformar a fim de exercitar a percepção, para vislumbrar a dimensão daquilo que os separa. Quem detém o poder de decisão sobre o futuro do estrangeiro Osman é a senhora Kottzmeyer-Göbelsberg. Com o poder que o estado the atribui, as decisões tomadas por ela têm um impacto substancial na construção de identidade de Osman e, com isso, em sua percepção da dignidade pessoal.

Nessa situação liminar, o tom e as palavras escolhidas por ela para aproximar-se do outro com informações de peso sugerem que este, em sua visão de mundo, não passa de um objeto cuja natureza diferente não merece o respeito ou a empatia concedida àqueles que pertencem ao grupo da detentora de poder. Esse comportamento, jocosamente ilustrado, não surge do nada e não está representado no universo diegético de forma gratuita ou somente com o desejo de recrear o leitor. Se as autoridades podem utilizar esse discurso pouco respeitoso é porque o espaço social cria um ambiente em que já não é necessário mascarar a hostilidade e o desprezo experimentado pelo estrangeiro. Como indicado no início deste artigo, uma das preocupações que movem o autor do romance é a xenofobia e sua repercussão na vida do imigrante. A xenofobia atrelada a pessoas de autoridade produz medo, uma vez que os poucos direitos que o imigrante tem se encontram assim ainda mais fragilizados, diante da possibilidade de arbitrariedade. Contudo, no lugar de sucumbir ao medo, o protagonista ri e afirma sua vitalidade, a despeito do perigo que se concretiza com uma intensidade cada vez maior.

Esse perigo se concretiza na possibilidade de extradição, embora o protagonista tenha passado mais de trinta anos legalmente no país. A reação da autoridade é de indiferença, mascarada de neutralidade e da necessidade de cumprir as leis:

Das tut mir schrecklich leid für Sie. Aber das sind nun mal Tatsachen, an denen wir nicht vorbeikommen! Ich kann da nichts machen. Es hat schon alles seine Richtigkeit, Sie müssen bis zum 25. Juni, 12 Uhr mittags, Deutschland verlassen haben. Ich kann das leider auch nicht ändern! (ENGIN, 2002, p. 18)3.

\footnotetext{
3 "Eu sinto terrivelmente muito pelo senhor. Mas esses são os fatos que não podemos ignorar! Eu não posso fazer nada. Tudo isso está bem certo. O senhor deverá ter deixado a Alemanha até o dia 25 de junho, às 12 horas. Infelizmente, eu também não posso mudar isso!".
} 
Na encenação dessa fala, há palavras que denotam empatia. Seu conteúdo, porém, se mostra vazio, pois todo o comportamento que perpassa a fala da funcionária sugere que o outro que verbaliza seu medo e apreensão já não passa de um número, cujas inquietações não a afetam. O discurso que legitima essa reificação do estrangeiro está arraigado no princípio da racionalidade, da sistematicidade e na crença de que a ordem da instância superior está inquestionavelmente certa. A indicação exata do horário em que o estrangeiro terá de deixar o país metonimicamente representa o endeusamento do Estado e suas verdades. Sua interpretação de mundo no princípio da exatidão milimétrica e, com ela, suas ordens que impõe limites aos desmandos infantis daquele que procura por um caminho alternativo, precisam ser cumpridas à risca, com uma seriedade impassível estampada no rosto. A seriedade e a argumentação aparentemente racional infundem medo, não somente por despertarem reminiscências do passado nazista, mas por se negarem a qualquer forma de diálogo e obliterarem a humanidade daqueles que não pertencem ao próprio grupo.

Esse apagamento da humanidade do estrangeiro é reforçado em outros episódios que compõem a realidade intratextual. Assim, durante a contratação dos primeiros trabalhadores turcos ainda na Turquia, estes são submetidos a exames para a comprovação de aptidão física (ENGIN, 2002, p. 23), com o objetivo de selecionar somente aquele material biológico capaz de um alto desempenho nas linhas de montagem, nos centros alemães de produção. Noutro episódio, os mesmos estrangeiros são convidados a participarem de experimentos de alto risco, para o fomento da pesquisa (ENGIN, 2002, p. 89). As preocupações éticas não permitem envolver nativos, mas não detecta problemas, em se tratando de estrangeiros. Já Güney Dal havia abordado esses temas em seu romance Wenn Ali die Glocken läuten hört. Essa política de dois pesos e duas medidas aparece num terceiro episódio, quando a família do protagonista turco é atacada por um grupo de skinheads. A polícia testemunha o ato de violência, mas prefere não interferir, pois para ela as vítimas parecem não ser dignas de proteção (ENGIN, 2002, p. 113). Os representantes da autoridade permanecem sérios e impassíveis. Assim, a pergunta da filha do protagonista tem todo sentido: "Papa, Papa, brennen die unser Haus jetzt auch ab?" / "Pai, pai, vão incendiar nossa casa agora?" (ENGIN, 2002, p. 107). O que num primeiro momento parece exagero típico da sátira, remete a acontecimentos reais de casos semelhantes noticiados por 
jornais de circulação nacional. O protagonista menciona "Hoyersweda, Rostock, Mölln, Solingen, Lübeck" e não perde a oportunidade de construir um paralelo com o tenebroso passado nazista (ENGIN, 2002, p. 08).

Nos quatro exemplos citados - no tratamento indiferente por parte dos funcionários do órgão responsável pelas questões dos estrangeiros, na seleção dos trabalhadores por representantes alemães na Turquia, na escolha de candidatos para experimentos de alto risco e, por fim, no comportamento da polícia diante de uma situação em que o estrangeiro é alvo explícito de violência - o corpo do outro se encontra ameaçado. A seriedade e todo o aparato que se esconde por trás desse modo de interação não somente servem para vigiar e controlar o corpo daquele que não pertence ao clube que administra a fonte de recursos, essa modalidade de encenação pessoal também é utilizada para mascarar omissões graves. Na posição de subjugado, o outro não tem acesso às informações privilegiadas de quem detém o poder, por isso seu corpo obedece diante do medo que o desconhecido infunde. O desejo de manter a integridade pessoal e obter recursos para concretizar sua existência o levam a curvar-se perante as diferentes formas de arbitrariedade legitimadas por um discurso racional e sério.

\section{A subversão e a renovação}

O início da rebelião contra o jugo está no corpo. Quando este já não suporta o excesso de controle e, sobretudo, quando experimenta reiteradamente a dor produzida pelos desmandos alheios, ele procura por caminhos que possam lhe devolver o prazer na existência. Esses caminhos, por vezes, passam por um processo solitário ou conjunto de reflexão, por meio do qual o sujeito começa a vislumbrar a distribuição de poder nas coordenadas do espaço social e a reconhecer modelos de interação baseados nessa hierarquia. A partir da consciência de um mundo desproporcional, cuja lógica primária é a obtenção e posterior defesa de fontes de prazer a partir de discursos legitimadores, o outro estrangeiro se dá conta de seu lugar e começa a interferir na produção de sentidos, com o objetivo de mudar sua situação. Nesse processo de renovação, precisa antecipar um reservatório significativo de energia por parte dos detentores de poder, já que poder e 
verdade estão intimamente entrelaçados, e divisar estratégias que evitem um embate frontal do qual certamente sairia derrotado.

$\mathrm{O}$ riso se revela interessante tanto como estratégia de ressignificação como de atitude existencial. Assim, na passagem inicialmente citada do primeiro encontro entre Osman e a senhora Kottzmeyer-Göbelsberg, a atitude existencial que o estrangeiro traz consigo não permite que o desprezo e o desrespeito o silenciem. Sua voz própria mantém a energia vital do riso, combatendo as tentativas de silenciamento e, o que é muito mais importante, de implantação da ideologia do mais forte em sua visão de mundo. O protagonista se dá conta da diferença de forças, mas nem por isso aceita sua subjugação. Essa atitude de afirmação da própria existência representa a base para reconhecer a igualdade de direitos e deveres, incluindo as convenções de respeito. Ao refletir sobre as opções linguísticas feitas pela funcionária, ele revela seu conhecimento sobre as diferentes práticas para a formação de sentido naquele espaço social. Assim, a utilização do pronome informal e a adaptação de sua fala ao estilo rudimentar, desrespeitosamente utilizado pela funcionária, representa um ato de resistência, cujo tom conciliador indica um desejo de negociação, mas, ao mesmo tempo, sugere que está muito longe de permitir que sua mente seja colonizada por meio da violência verbal.

Nesse comportamento de resistência, o protagonista ressignifica os sentidos assentados e a distribuição de lugares de fala. O papel do incivilizado, cuja falta de conhecimento da cultura humana aparentemente legitima a adoção de um outro peso no tratamento, subversivamente reflete sobre aquela que se crê no berço da civilização, cujos valores e verdades precisam ser defendidos contra os interesses bárbaros de estrangeiros. Ao recusar o papel a ele atribuído e utilizar o mesmo conjunto de sentidos inerente ao papel do subordinado para dirigir-se à detentora de poder, Osman cria uma situação de tensão, em que os sentidos perdem sua fixidez, para confluírem num processo dinâmico de redefinição ou, ao menos, de questionamento. Esse movimento subversivo de resistência desconstrói a configuração hierárquica arraigada na visão de mundo da funcionária, embora ela permaneça convicta de sua superioridade, e expõe a cegueira ideológica que estabelece os modelos comunicação naquele espaço social. Mais tarde, o protagonista estende o círculo de ataque: 
Ebenso wie der Torero, läßt auch Frau Kottzmeyer-Göbelsberg immer wieder neue Ausländer schutzlos in ihre Arena. Die deutsche Mitbürger und der Gesetzgeber sind dabei die Zuschauer, und ich bin der blutende, schnaufende Stier. Alle warten sehnsüchtig darauf, wie ich mit einem letzten Dolchstoß endgültig fertiggemacht werden, um dann voll befriedigt ausschreien zu können:

"Oleeeeyy!!" (ENGIN, 2002, p. 127)4.

Como a funcionária pública, também os cidadãos e o legislador têm seus papéis subversivamente invertidos. A escolha de termos do discurso político reforça a seriedade e o pertencimento a um grupo cuja preocupação é a organização do bem-estar do espaço social em questão. Sua aproximação aos espectadores de touradas os contradetermina, atualizando a imagem de uma seriedade extasiada, diante de outro ser transformado em objeto. Nesse contexto, a seriedade já não representa uma estratégia de encenação social para a imposição de uma verdade, ela incorpora o arrebatamento que se produz com a excitante sensação de poder, ao testemunhar o corpo alheio manipulado pela vontade de um terceiro. Para isso, a reflexão ética se encontra neutralizada, dando lugar a uma indiferença que permite o deleite com a dor do outro. Se o comportamento dos detentores de poder sugere que, além do poder, também detém uma visão mais ampla, embasada na crença em uma capacidade mais extensa de abstração, a passagem citada indica justamente o contrário, subvertendo o monopólio do intelecto, a fim de indicar que a cegueira cognitiva grassa também entre aqueles que definem o que deve ser visto.

Nessa inversão dos atributos, há um empenho bastante próximo àquilo que a crítica pós-colonial se propõe a fazer. O representante do centro imperial e emissário das verdades universais define o sujeito que vive às margens coloniais como alguém que apresenta, de acordo com a interpretação de Edward W. Said, uma "disposição à irracionalidade, sensualidade, decadência, feminilidade, despotismo, brutalidade" (KREUTZER, 1995, p. 203). O senhor imperial atribui ao sujeito de suas colônias atributos que negam o pertencimento ao círculo dos civilizados, legitimando com isso uma política de exclusão e

\footnotetext{
4 "Como o toureiro, a senhora Kottzmeyer-Göbelsberg sempre deixa novos estrangeiros entrarem desprotegidamente na arena. Os cidadãos alemães e o legislador são os espectadores, e eu sou o touro sangrento e ofegante. Ansiosamente, todos esperam que acabe comigo com uma punhalada final, para então, completamente satisfeitos, poderem gritar: "Oleeeeyy!!".
} 
fomentando uma visão parcial, cega às barbáries cometidas longe de casa. O protagonista de romance aqui analisado reverte essa visão desproporcionada, mostrando um senhor imperial irracional, decadente, brutal e que se deixa levar por impulsos muito distantes de serem controlados por um discurso de civilização. O leitor pode-se questionar se é lícito transferir esse aparato heurístico delineado para a análise de macroestruturas intercontinentais para um contexto intranacional, com uma coloração bastante local. Argumenta-se aqui que sim, pois o modelo de interação identificado pelos críticos póscoloniais para um contexto mais amplo é igualmente identificável em microcosmos sociais, em que o direito de definição e instauração de verdades é unilateral. Com a inversão dos papéis e uma caracterização estranhada do senhor imperial, acontece a desconstrução das essências que engessam a visão de mundo. Nesse movimento subversivo, partindo do sujeito colonial, também os sentidos perdem sua estabilidade, para mergulharem num processo de redefinição. Este traz consigo uma reconfiguração das coordenadas sociais e das possibilidades de narração identitária para os dois partidos, cujo poder sofreu alterações.

Além da inversão, o processo de renovação se dá por meio de uma aproximação subversiva ao comportamento do detentor de poder:

Wir beide möchten uns entschuldigen für unsere Landsmännin. Da gibt es so viele Brücken und Hochhäuser in der Stadt, aber diese Ausländer müssen immer hier runterspringen. Uns persönlich ist das sehr peinlich.

Ja, das ist wirklich grauenhaft, klagt Frau Kottzmeyer-Göbelsberg verschwitzt, ohne uns anzugucken, nicht mal bei dem Wetter dürfen wir die Fenster aufmachen. Entweder stürzen die Moskitos von außen rein, oder die Ausländer von oben runter! Aber die Behördenleitung hat schon was dagegen getan", und sie deutet auf ein großes Schild neben dem Fenster: "Runterspringen während der Arbeitszeit untersagt!" (ENGIN, 2002, p. 157).5

\footnotetext{
5 "Nós dois queremos nos desculpar por nossa conterrânea. Há tantas pontes e prédios na cidade, mas esses estrangeiros sempre têm que pular daqui. Para nós, isso é bem embaraçoso."

"Sim, isso realmente é horrível", lamenta a senhora Kottzmeyer-Göbelsberg toda suada, sem olhar para a gente, "nem com esse tempo podemos abrir as janelas. Ou os mosquitos se lançam de fora para dentro ou os estrangeiros de cima para baixo! Mas a direção do órgão já tomou uma medida", e indica uma grande placa ao lado da janela: "Está proibido pular da janela durante o expediente!"
} 
A tentativa de captação de benevolência sugere à funcionária que os estrangeiros se identificam com os valores que ela representa. Isso implica que a forma como as personagens expõem suas desculpas se dá com seriedade, a ponto da senhora KottzmeyerGöbelsberg não se dar conta da ironia em suas palavras. Da mesma forma como os detentores de poder encobertam por trás da seriedade um mundo que protege suas fontes de recursos, os estrangeiros do universo intraliterário aprenderam a esconder suas opiniões por meio de expressões faciais sérias, com intuito de assegurar sua dignidade. Mais subversivo aproximarem-se do horizonte de valores da interlocutora. Aparentemente a preocupação ética se transformou num discurso vácuo, em que a vida do outro é menos importante que o bem-estar dos funcionários. Numa mesma linha de pensamento, mosquitos e estrangeiros são mencionados como incômodos que os forçam a renunciar ao ar fresco. A colocação da placa reforça a desproporção, sugerindo a presença de um estado cuja visão é parcial, produto de um comportamento racionalista completamente bestial.

$\mathrm{O}$ protagonista estrangeiro, contudo, não parte para o ataque para nomear as incongruências existentes naquele espaço nem se arroga criticar os detentores de poder. No lugar de uma luta condenada à derrota, ele se aproxima com o riso mascarado que afirma sua existência e não permite que sua mente seja colonizada. Nessa forma de interação, o protagonista bloqueia a reprodução inconsciente da ideologia senhorial e constata, com seus avanços irônicos, quão frágil é a disposição de mundo que lhe dita as regras da vida. Com base nesse conhecimento, ele impede que a violência sofrida ameace sua dignidade e cria uma nova rede de signos que renova o contexto em que está inserido.

\section{Considerações finais}

Com sua sátira, Engin distorce, exagera e ridiculariza um excerto da sociedade alemã. No centro de sua atenção está o estrangeiro e seus problemas com a xenofobia e com um estado completamente burocratizado que se nega a ver o sujeito. Na concepção do protagonista, o autor não tenta simplificar o papel do estrangeiro, reduzindo-o ao lugar da vítima. Os estrangeiros que habitam o universo intraliterário de Engin antes lembram os pícaros de Grimmelshausen, que certamente sofrem com os desmandos alheios, mas que estão muito longe de representarem um modelo de comportamento. $\mathrm{Na}$ representação 
negativa dessas duas forças que se chocam, Engin fustiga a cegueira e a parcialidade, criticando especialmente a falta de engajamento pelo bem de todos.

Justamente essa crença na importância do desenvolvimento do potencial humano, abordada na entrevista citada no início deste artigo, motiva o autor a expor de modo ampliado alguns problemas que caracterizam as interações de órgãos públicos com os estrangeiros e as interações dos estrangeiros com a nova cultura em que transitam. Nesse sentido, a recorrente lembrança do passado nazista e suas reaparições mascaradas na aproximação com o estrangeiro contêm um momento óbvio de crítica, mas implicam também que o espaço social criticado no universo extraliterário apresenta, no ponto de vista do autor, um potencial de transformação, no qual aposta ao desproporcionar os problemas. Essa e outras sátiras escritas por Engin têm um claro interesse de engajamento social, alimentando o desejo de melhorar o espaço em que foram produzidas. O caminho adotado por Engin para essa transformação não é o confronto hostil nem a lamentação sobre o próprio estado (BOWER, 2012, p. 194), mas o riso renovador que ainda crê no humano.

\section{REFERÊNCIAS}

BOWER, Kathrin. Serdar Somuncu: Reframing Integration through a Transnational Politics of Satire. In: The German Quarterly, 85 (2), 2012, p. 193-213.

ENGIN, Osman; YEŞILADA, Karin. Künstler oder Moralapostel? Inteview mit Osman Engin. In: Die Tageszeitung, de 13 de dezembro de 1994. Disponível em: http://www.osmanengin.de/presse_interviews.html. Acesso em: 12 out. 2014.

ACKERMANN, Irmgard. Germans viewed as foreign: the representation of the 'Other' in 'Ausländerliteratur'. In: World Literature Today, 69 (3), 1995, p. 528+. Academic OneFile.

BAKHTIN, Mikhail. A cultura popular na Idade Média e no Renascimento: o contexto de François Rabelais. Tradução: Yara Frateschi Vieira. São Paulo: Hucitec, 1987.

ENGIN, Osman. Kanaken-Gandhi. München: Deutscher Taschenbuch Verlag, 2002.

KREUTZER, Eberhard. Theoretische Grundlagen postkolonialer Literaturkritik. In: NÜNNING, Ansgar (ed.). Literaturwissenschaftliche Theorien, Modelle und Methoden. Trier: Wissenschaftlicher Verlag Trier, 1995, p. 199-213. 
TERKESSIDIS, Mark. Kabarett und Satire deutsch-türkischer Autoren. IN: CHIELLINO, Carmine (ed.). Interkulturelle Literatur in Deutschland. Ein Handbuch. Stuttgart/Weimar: J. B. Metzler, 2007, p. 294-301.

YEŞILADA, Karin. Schreiben mit spitzer Feder - Die Satiren der deutsch-türkischen Migrationsliteratur. IN: REULECKE, Jürgen (ed.). Spagat mit Kopftuch - Essays zur deutsch-türkischen Sommerakademie. Hamburg: Edition Körber Stiftung, 1997. 